\title{
Princípios orientadores da formação humana: dimensão normativa da educação
}

\author{
José Policarpo Junior ${ }^{1}$ \\ Maria Lucicleide Falcão de Melo Rodrigues \\ Universidade Federal de Pernambuco, Recife-PE, Brasil
}

\begin{abstract}
Resumo: Este trabalho promove uma reflexão sobre princípios que fundamentam a natureza da educação, embora nem sempre sejam adequadamente considerados pelo campo educacional em sua dimensão teórica e científica. Esses princípios - igualdade, verdade, utilidade, razoabilidade, introspecção, individuação e liberdade - são concebidos como elementos da dimensão normativa da educação. Tal dimensão apresenta-se como uma atualização do conceito de arete que guiou a construção espiritual da noção de Paidéia grega, raiz histórica do conceito de educação. Embora aqueles princípios não constituam uma lista completa da compreensão da educação, eles são necessários para sua legitimação como um campo próprio de saber e prática.
\end{abstract}

Palavras-chave: formação do indivíduo, verdade, individuação, liberdade.

\section{Human development guidelines: normative dimension of education}

\begin{abstract}
This study analyses some underpinning principles of the nature of education, although the educational field seldom considers them in their theoretical and scientific dimensions. These principles: equality, truth, usefulness, reasonableness, introspection, individuation and freedom are conceptualized as elements of the normative dimension of education. This normative dimension is considered an updated concept of arete, which guided the spiritual construction of the ideal of the Greek Paideia, the historical root of the concept of education. Although those principles do not constitute a complete list of the understanding of education, they are necessary to legitimate education as a field with its own knowledge and practice.
\end{abstract}

Keywords: individual formation, truth, individuation, freedom.

\section{Principios orientadores de la formación humana: dimensión normativa de la educación}

\begin{abstract}
Resumen: Este trabajo analiza principios fundamentales de la esencia de la educación, aunque el campo educativo raramente los considere teorica y cientificamente. Se conceptuan tales principios como elementos de la dimensión normativa de la educación, a saber: igualdad, verdad, utilidad, racionalidad, introspección, individuación, y libertad. Esta dimensión normativa es considerada como un concepto actualizado de arete, que ha guiado el edificio espiritual del ideal de Paideia, raíz histórica del concepto de la educación. Aunque esos principios no sean una lista completa para la comprensión de la educación, ellos son necesarios para legitimarla como un campo con su propio conocimiento y práctica.
\end{abstract}

Palabras clave: formación del individuo, verdad, individuación, libertad.

Este artigo tem por objetivo contribuir com o esclarecimento conceitual da educação por intermédio de uma argumentação intrínseca a seus próprios objetos. Embora tal empreendimento seja de natureza teórica, as razões para sua realização derivam também de aspectos práticos.

Quem esquadrinhar o campo educacional, tal como o mesmo se expressa em instituições científicas e acadêmicas, não terá grande dificuldade em perceber: a diversidade de temáticas e subtemáticas tratadas; variadas formas de investigação, sem um corpo teórico-metodológico comum e claramente aceito; diferentes privilégios concedidos a outros campos científicos, muitas vezes sem admitir o caráter científico do próprio campo educacional; teorias dissonantes ou com pouca conexão entre si. Resumidamente, depreende-se de tais fatos a existência de um fenômeno que poderia, no

\footnotetext{
1 Endereço para correspondência:

José Policarpo Junior. Instituto de Formação Humana. Rua Silveira Lobo, 32, CP 146. Poço. CEP 52.061-030. Recife-PE, Brasil. E-mail: jpj@formacaohumana.org
}

mínimo, ser denominado de imprecisão conceitual do próprio campo educacional. Por outro lado, tal manifestação institucional de indefinição dos limites e natureza intrínseca do campo educacional termina por também se refletir no conjunto das práticas que estruturam a vida docente, escolar e de formação do educador.

Este artigo não tem, obviamente, a pretensão de resolver os problemas mencionados quanto ao campo educacional. Também não é sua intenção problematizar diretamente razões e conseqüências da fragilidade conceitual desse campo. No entanto, admite-se aqui, como pressuposto, a existência da fragilidade teórico-conceitual da educação como campo próprio de estudo, pesquisa e intervenção no panteão científico. Diante disso, é objetivo deste artigo fornecer uma contribuição ao entendimento teórico intrínseco à educação, por meio de uma reflexão sobre princípios admissíveis à prática educacional nem sempre adequadamente valorizados pela educação em sua dimensão teórica.

Para a realização dessa tarefa, utilizar-se-á, como instrumento explicativo, a idéia de dimensão normativa da 
educação elucidada pela reflexão a respeito de alguns dos seus princípios fundamentais, tais como: igualdade, verdade, utilidade, razoabilidade, introspecção, individuação e liberdade. A idéia de dimensão normativa apresenta-se aqui como uma atualização do conceito de Arete que informou e dirigiu a construção espiritual e civilizatória da noção de Paidéia, principal idéia-força das raízes históricas do conceito de educação (Jaeger, 1936/2001). Na Grécia antiga e clássica, as raízes e o desenvolvimento da idéia de educação estavam inextricavelmente relacionados àquele conceito, $\mathrm{o}$ qual expressa o sentido de excelência, virtude e alcance de um fim relativo à função ou estrutura intrínsecas a algo ou a um ente determinado. $\mathrm{O}$ conceito tem, portanto, o poder de demonstrar a conexão necessária entre uma condição dada ou existente e o desenvolvimento apropriado à primeira. Com essa referência conceitual, apresenta-se, neste artigo, a idéia de dimensão normativa da educação derivada de uma reflexão sobre os princípios que se justificam como necessários à vida humana. Admite-se aqui, embora não haja espaço para o detalhamento de tal reflexão, que uma das causas da falta de esclarecimento conceitual e demarcação do campo educacional reside precisamente na ausência de clareza sobre tal dimensão normativa, fato que, por sua vez, se relaciona ao abissal desconhecimento livremente consentido sobre as origens e trajetória histórica da idéia de educação e de formação humana, inclusive no âmbito interno do próprio campo educacional. Tal aspecto será tratado em outro trabalho, juntamente com uma reflexão preliminar sobre os modos pelos quais os princípios da dimensão normativa da educação poderiam vir a ser praticamente (práxis) vivenciados e apropriados.

\section{Dimensão normativa da educação}

De acordo com os termos introdutórios precedentes, um aspecto fundamental da educação sem o qual se torna praticamente impossível compreender a natureza intrínseca do educar é a sua dimensão normativa. Não se pode sequer pensar na educação, quer do ponto de vista teórico, quer do prático, sem pressupor que a mesma está fundada na admissão de que o ser humano deve atingir uma determinada condição que ainda não se encontra desenvolvida, atualizada ou presente. A definição da natureza dessa condição a ser atingida não goza, entretanto, de consenso no interior do campo educacional. A assunção de que a educação não pode ser concebida, nem existir como prática, sem essa dimensão normativa é, entretanto, um princípio que pode fazer emergir resistência da mentalidade científica em geral quanto ao caráter científico do campo educacional.

Devido a razões de ordem histórica, social, econômica e cultural, cuja discussão detalhada extrapolaria o âmbito deste artigo, a ciência sofreu, ao longo dos séculos, uma conversão progressiva ao estudo daquilo que é, ou seja, que existe independentemente do sujeito e que está despido de toda consideração quanto ao que deve ser. Segundo tal entendimento, a razão científica é aquela capaz de apreender o fenômeno objetivo de forma independente do modo pelo qual o sujeito a ele tem acesso. É necessário afirmar, entretanto, que essa é uma caracterização determinada do modo de a razão se afirmar no mundo e na cultura moderna, embora não tenha sido sempre assim e nem tal compreensão da razão seja total e exaustiva (Horkheimer \& Adorno, 1944/1985; Marcuse, 1966/1979). A educação, entretanto, diferentemente talvez de outros campos científicos nas ciências humanas e naturais, é um campo de saber e de prática que não pode subsistir sem a admissão de sua normatividade. Essa dimensão é, portanto, algo cuja expressão não consiste apenas em descrever aquilo que é, mas exige também admitir uma direção para aquilo que deve ser. Nesse ponto, entretanto, é importante reconhecer que algumas outras áreas também se fundam nessa normatividade intrínseca, como é o caso da medicina e da psicanálise; além de investigar seu objeto próprio, assentamse na compreensão de que seu objetivo último consiste em proporcionar ou manter a saúde e o bem-estar físico das pessoas e a autonomia e autodeliberação do sujeito - ou seja, não podem tomar por fundamento apenas aquilo que é, mas precisam também considerar sempre o que deve ser. Por essa razão, Castoriadis (1990/1992), certa vez retomou a afirmação freudiana da impossibilidade da política, da psicanálise e da pedagogia, pois, considerando o modo sui generis como cada uma delas se estabelece, percebe-se que as três tomam por pressuposto sempre algo que ainda não está dado, a saber: uma sociedade livre e auto-organizada, um sujeito livre e autodeliberativo, uma pessoa livre e humanamente formada.

Uma vez admitida a dimensão normativa da educação, nada ainda pode ser dito quanto ao seu conteúdo, isto é, quanto aquilo para o que aponta o seu dever-ser. Esse aspecto ocasiona grande mal-estar entre os próprios educadores, uma vez que não há para ele uma resposta simples. Para a falta de clareza ou convicção quanto à dimensão normativa da educação também contribui o fato de diferentes vozes externas ao campo educacional se acharem em plenas condições de propugnar aquilo que acreditam ser a tarefa intransferível do educar. Como inexiste uma clareza sobre a importância e a natureza daquela dimensão no próprio campo educativo, fácil se torna a qualquer um anunciar a meta educacional que lhe parece mais conveniente ou adequada. Assim, para fazer referência apenas às últimas décadas, algumas das finalidades educativas apregoadas com muita influência, no Brasil, foram: a produção de capital humano, a revolução ou transformação social, a formação para a democracia, a cidadania, as competências e a formação do sujeito aprendente. Não se deve negar a pertinência de nenhum desses objetivos, nem mesmo sua relação determinada com a tarefa educativa. No entanto, é mister reconhecer que todas essas finalidades se originam de preocupações exteriores à educação, ou de outros campos de saber - como a economia, sociologia, ciência política, psicologia - que não a própria educação. Assim, para que seja possível visualizar a direção do conteúdo normativo da educação, é imprescindível explicitar e entrar em acordo, 
ainda que em linhas gerais, a respeito daquilo mesmo que viria a definir sua natureza e escopo. Em outros lugares (Röhr, 1999; Organização das Nações Unidas para a Educação, a Ciência e a Cultura [UNESCO], 1996/2003) essa discussão já foi iniciada e embora este autor nutra concordância com as idéias ali expressas, optou-se aqui por apresentá-las com uma linguagem própria capaz de, em princípio, tornar-se mais facilmente assimilada pelas idéias-guia hipoteticamente valorizadas por nossa sociedade e cultura.

\section{Fundamentação da dimensão normativa da educação: a formação humana}

Todos os seres humanos surgem em meio a um mundo que a eles se apresenta como um contexto vital que se lhes poderá revelar receptivo ou ameaçador. De outro lado, para surgir nesse mundo, o ser humano precisa do concurso de uma relação entre, no mínimo, duas outras pessoas. A mera sobrevivência física do ser humano recém-chegado a esse mundo vai depender fundamentalmente desse primeiro contexto que o acolhe amistosamente ou não. Do ser recémchegado serão demandados, explícita ou implicitamente, regras, modos de conduta e valores referentes à natureza desse contexto que o abriga. Assim, de forma ampla ou restrita, o ser humano é, desde sua origem, um ser que se encontra em relação. Em grande medida a qualidade de sua vida dependerá da forma, natureza e intensidade que imprimir a tais relações; o empreendimento humano dependerá necessariamente da intensidade de aprovação ou desaprovação do contexto inter-relacional em que se encontra submetido. Entretanto, a capacidade de apreensão da extensão da rede de conexões responsável pela existência do ser particular pode ser ampla ou restrita. Desse modo, uma pessoa pode compreender ou não que sua própria sobrevivência mantém, por diversas mediações, vínculos com pessoas que praticam o extrativismo vegetal, por exemplo, em um país que se encontra a milhares de quilômetros do lugar em que vive; pessoas essas com as quais provavelmente jamais venha a ter algum relacionamento pessoal. Assim, um indivíduo em particular pode ter essa compreensão ou não. Via de regra, no entanto, as pessoas acreditam ter relação de dependência apenas com os contatos pessoais que pode pessoalmente identificar. Por isso não é raro que o modo como o sujeito particular se concebe a si mesmo e os laços de lealdade que nutre para com algum coletivo sejam ambos definidos com base nessa percepção relativa a sua condição de dependência conhecida. Surgem assim os principais rudimentos de uma concepção de si estruturada por tais relacionamentos pessoais e pela representação mental dos mesmos. Desse modo, crianças bem novas passam a se sentir judias, muçulmanas, palestinas, brasileiras, pertencentes a esta ou àquela comunidade. A depender do modo e alcance como o ser particular apreende a teia de relações que o mantém vivo, surgem ou não rivalidades e inimizades entre os modos pelos quais outros seres se vêem a si mesmos no mundo.
Do exposto, resulta que, em maior ou menor grau, todo ser particular depende necessariamente do cultivo de um determinado modo de estar e viver entre os humanos e a natureza. Em outras palavras, todo ser humano necessita cultivar uma ética que será tão ampla ou tão restrita quanto for sua representação mental da tessitura inter-relacional em que se encontra. Esse aspecto da condição humana reveste-se, assim, em dimensão importante da normatividade educativa. No relatório Delors (UNESCO, 1996/2003), essa dimensão é discriminada como a aprendizagem para "viver juntos". Assim, a própria condição humana exige tal aprendizado, embora muitas vezes as situações sociais restrinjam enormemente a amplitude desse "viver juntos" para, no máximo, os limites de uma aldeia, de uma família, de uma classe ou de alguma coletividade. Quanto a isso, há uma dimensão educativa a respeito da qual muitas vezes haverá discrepância e mesmo oposição entre os ideais e normas sociais, em níveis mais restritos ou mais amplos, e os ideais educacionais. Esse é também um dos obstáculos que, ao lado de outros que ainda serão discriminados a seguir, implicam a diferenciação conceitual entre educação e socialização, uma vez que nem sempre os conteúdos e metas de ambas serão convergentes.

\section{O princípio da igualdade}

Segundo o exposto, a educação emerge como aquela prática orientada que permite visualizar, em toda a diferença, uma igualdade fundamental de dignidade, integridade e direitos. Nesse ponto, a socialização abandonada a si mesma estenderá esta igualdade apenas aos limites espaciais, históricos, sociais e culturais que definem uma determinada identidade coletiva, enquanto à educação caberá ampliar o mais possível aquele atributo à totalidade dos seres humanos e ao próprio ecossistema envolvente. Quando a educação se subsome completamente aos ditames de uma sociedade ou cultura, aquela dimensão educativa praticamente se extingue, o que necessariamente implica a falsificação da prática e do próprio conceito do educar. Uma vez que esse acontecimento não é raro na educação, a teorização sobre o educar muitas vezes termina por consagrar essa subordinação da educação aos ditames sociais e culturais - como acontece com a reflexão de Brandão (1983) que concebe a educação como uma socialização direcionada -, legitimando, assim, ainda que em termos conceituais, a falsificação do conceito e da prática educacionais, o que termina por levar ao impedimento da visualização de práticas educativas concebidas segundo seu sentido intrínseco e não apenas de acordo com as determinações sociais e culturais existentes. Desse modo, a tendência teórica que se dá por satisfeita em demonstrar esta determinação do fenômeno do educar, sanciona, então, em nome de um pseudo-realismo, ou de um pretenso combate ao idealismo, a própria condição atrofiada em que a educação se encontra em tal contexto.

Assim, pode-se dizer que essa primeira dimensão normativa da educação (o princípio da igualdade que surge da 
compreensão da interconexão ampla com inumeráveis seres e situações), que não necessariamente estará sempre em contradição com sua dimensão factual existente, é algo próprio do educar e não deriva simplesmente dos saberes coligidos nos campos conceituais da sociologia, da política, da psicologia, da economia, nem da filosofia.

\section{Os princípios da verdade e da utilidade}

Associada a essa compreensão da ampla interdependência entre os seres humanos e o princípio da igualdade daí decorrente, encontra-se a dimensão do conhecimento e seu princípio orientador que é a busca da verdade. Tal princípio está também relacionado à condição da vida humana.

Ao se fazer um retrospecto histórico e filosófico, podese reconhecer a legitimidade da afirmação de que a razão sempre nutriu o "projeto de dissipar a ignorância e superstição e fazer dos homens senhores" (Horkheimer \& Adorno, 1944/1985, p. 19). Em outras palavras, a razão, como dimensão básica do conhecer e do pensar, não se expressa inicialmente, nem em muitos outros momentos históricos, como fim em si mesma, nem como mero instrumento para outros fins que não fosse o do aperfeiçoamento e emancipação dos seres humanos. Isto significa que por mais que a razão tenha se desenvolvido e se disponibilizado nas instâncias subjetivas de cada sujeito particular e nas manifestações objetivas das realizações tecnológicas, infra-estruturais e culturais, ela não realiza seu objetivo intrínseco enquanto tais expressões subjetivas e objetivas não estiverem articuladas e a serviço do progresso e aperfeiçoamento da humanidade e do mundo em que esta habita. A dimensão da verdade não está dissociada desse entendimento.

A assunção de tal princípio tem implicações para a compreensão do estatuto de verdade, na medida em que faz com que a esta também corresponda uma dimensão do dever-ser e não apenas daquilo que é. O que Marcuse (1941/1978) identificou na razão concebida segundo a dialética hegeliana vale também aqui, a saber, o entendimento de que a verdade não se encontra apenas no nível dos fatos, mas aponta igualmente para um estado de coisas em que o julgamento subjetivo não está divorciado da objetividade, mas, ao contrário, comunga com esta em uma relação pacífica. Nesse caso, o juízo que diz o que algo é, não exprime apenas uma propriedade ou condição temporária e identificável no presente momento, mas assinala também uma antecipação conceitual da condição que o objeto tende a alcançar segundo sua própria essência e devir histórico. Para a atual discussão, interessa entender que a busca da verdade não se encontra limitada à asserção do que um objeto ou situação supostamente possa ser, independentemente de qualquer outra coisa. Sem desprezar esse aspecto, a verdade também é a antecipação ou o anúncio de que o conhecimento - derivado de todas as capacidades humanas disponibilizadas histórica, social, cultural e individualmente - encontra sua realização no modo como ele serve ao aperfeiçoamento humano. Do exposto, portanto, pode-se afirmar que nem tudo o que se manifesta como objetivação das capacidades cognitivas, abstratas e instrumentais do gênero humano é de fato verdadeiro na acepção rigorosa do termo.

O Relatório da UNESCO (1996/2003) afirma que estão entre os fins precípuos da educação o "aprender a conhecer" e o "aprender a fazer". À luz da reflexão antecedente, é possível identificar como princípios orientadores dessas duas finalidades, a verdade e a utilidade. Embora muito se tenha debatido sobre a relação conflituosa entre verdade e utilidade na história da filosofia, para os propósitos deste texto importa realçar o quanto ambos os princípios se interpenetram e complementam. No sentido estrito da idéia de verdade apresentada anteriormente sobressai-se a própria característica da utilidade. Considerando as relações dos seres humanos entre si e destes com o ecossistema, a verdade que se manifesta como a síntese do que é e do que deve ser reveste-se também do sentido da utilidade que serve ao propósito do progresso e aperfeiçoamento humanos. De acordo com esse entendimento, o útil é verdadeiro e a verdade é também o que é útil.

Grande parte do conflito entre esses dois princípios baseia-se na particularização da amplitude de um deles ou de ambos. Assim, por exemplo, o que se configura de grande utilidade na esfera econômica, e que pode ser verdadeiro na ordem de coisas existente, não necessariamente atenderá ao sentido normativo da verdade que implica um devir humanizador e harmônico entre os entes particulares e o contexto que os abrange. Por outro lado, é um grande desafio para toda verdade alcançada em um campo particular vir a tornar-se também útil em sua generalidade. Tal coincidência exige, entretanto, o critério da experiência - o que também tem seus motivos, pois, como já afirmado, a razão e o juízo não são finalidades em si mesmos, mas apontam para aquele momento de pacificação e harmonia entre as dimensões subjetiva e objetiva que só pode surgir por meio da experiência compreendida em seu sentido histórico, social, cultural, instrumental, mas também, existencial. Apesar disso, há que se reconhecer que se a coincidência a priori da verdade e utilidade for tomada como critério absoluto para a legitimidade de ambas, corre-se o risco de se abandonar toda iniciativa séria de progresso humano que não puder ser ainda experimentada em sua generalidade. Mas como os homens em meio ao mundo encontram-se ainda na imperfeição e em um estado que por si só justifica a existência da educação, essa própria generalidade existente não pode, portanto, constituirse em representante final e exclusiva do critério da utilidade, porque aquilo que se configura útil no estado atual não necessariamente reveste-se do sentido daquela utilidade que, aliada à busca da verdade que pressupõe uma realidade pacificada, só pode ser apreendida do ponto de vista normativo da formação humana.

Assim, as finalidades do "aprender a conhecer" e "aprender a fazer" não estão divorciadas do objetivo de "aprender a viver juntos", de forma que as dimensões normativas da busca da verdade e da utilidade estão igualmente articuladas à dimensão normativa da ética. Destarte, apenas 
no sentido daquilo que é útil e verdadeiro ao desenvolvimento e aperfeiçoamento dos seres no mundo, o conhecimento e a tecnologia se justificam. O saber é ético e a ética é também sábia, por mais que tais princípios nem sempre sejam triviais e auto-evidentes em todas as circunstâncias.

\section{Princípio da razoabilidade}

Do exposto se segue necessariamente que a verdade, como aspecto axiológico da atividade do conhecer, se expressa como condição normativa não apenas da apreensão daquele estado de coisas existente numa dada situação, mas também como resultado de um esforço que, ao apresentar-se como o "conhecimento" de algo, viabiliza a possibilidade de este algo se constituir no bem mais amplo possível que possa ser propiciado aos potenciais beneficiários. É deste modo que, por exemplo, o conhecimento mais acurado da natureza do câncer, ainda que seja processado por técnicos e cientistas nas mais "frias" condições de laboratório, encontra sua legitimidade maior no benefício que irá proporcionar a muitos que venham a ser acometidos por este mal. Nesse caso, a verdade do conhecimento de um estado de coisas específico encontra sua plena justificativa no âmbito maior dos seus possíveis beneficiários. É desse modo que, no caso, a verdade e a utilidade se harmonizam como atributos intrínsecos e inegáveis do conhecimento, embora certamente haja casos, como na energia nuclear, por exemplo, em que nem sempre a ausência de conflito entre os critérios da verdade e da utilidade estará assegurada, pois muitas vezes, em nome da justificativa nobre de se ter acesso à tecnologia nuclear para melhorar a vida civil, esforços são empreendidos para a produção de tecnologia militar.

Portanto, ainda que se admita que a percepção limitada de um problema possa, nesse âmbito restrito, ser considerada útil e/ou verdadeira, é mister se ter em mente que, mesmo em uma situação particular, são muitos os aspectos que precisam ser considerados por um juízo que almeje a conotação de verdade. Desse modo, a verdade e a utilidade também estão associadas ao princípio da razoabilidade, o qual não é mais tão somente da natureza do conhecer, mas, principalmente da natureza do pensar.

Assim, como síntese parcial do que foi apresentado até aqui, compreende-se o princípio da igualdade como associado ao reconhecimento da dignidade de todos os sujeitos particulares diante dos quais cada ser humano se encontra como um ponto de expressão de uma imensa rede de interdependência; identificam-se os princípios da verdade e da utilidade, como regentes da natureza da atividade cognitiva compreendida na condição de beneficiar a vida e os seres humanos, e; o princípio da razoabilidade como algo que se associa a e ilumina os próprios critérios da utilidade e verdade.

A razoabilidade, portanto, não é o resultado assegurado de um juízo que discrimina o que um objeto supostamente é, mas trata-se, antes, daquela dimensão que se caracteriza por um diálogo "sem som de mim comigo mesmo" (Arendt,
1971/2000, p. 59). Essa mesma autora sugere a hipótese (Arendt, 1971/2000) de que uma condição possível para que o mal prospere ou se torne banal resida na ausência de reflexão por parte dos sujeitos. Por essa razão, no livro em que narra e analisa o julgamento de um oficial nazista por uma corte israelense (Arendt, 1963/1999), a referida autora admirou-se porque esperava encontrar um monstro que seria revelado como autor de inúmeras atrocidades. Ao invés disso, para a surpresa de muitos, no lugar de um monstro havia ali apenas um homem comum cuja mente se caracterizava pela incapacidade contumaz de refletir. Tratava-se de alguém afeito a clichês e frases prontas, incapaz de analisar qualquer coisa a não ser pela ótica estreita das palavras de efeito. Aquele ser, segundo a análise arendtiana, era incapaz de exercitar o pensar como atividade caracterizada pela dualidade interior do refletir; por isso, restava-lhe tudo representar e expressar por meio das frases feitas e do repertório de respostas prontas e automáticas que trazia consigo. Assim, embora não afirmasse que o cultivo da capacidade de reflexão influenciasse a prática do bem, a autora reconhecia que pelo menos o seu não-exercício poderia contribuir significativamente para a prática do mal.

Segundo o exposto, é mais do que admissível supor que haja diversas situações em que os princípios da verdade e da utilidade não sejam auto-evidentes, mas precisem ser iluminados pela razoabilidade advinda da reflexão. Desse modo, por exemplo, por meio da reflexão alguém pode vir a alcançar a significação que o auxiliará a decidir sobre a utilidade de aprimorar-se nessa ou naquela habilidade para seu próprio bem e para o bem dos demais com quem conviva e mesmo para o bem de pessoas que desconheça e que jamais conhecerá. Por meio do refletir, é possível se encontrar os meios mais adequados ou mais significativos para se superar obstáculos sociais, culturais, econômicos ou políticos que impeçam o estabelecimento de vínculos humanos genuínos nas relações sociais e interpessoais. Assim, embora os juízos advindos da reflexão não sejam de mesma natureza dos oriundos da cognição e da adequação à utilidade, são eles, entretanto, que conferem significado e direção à ação e ao modo de estar no mundo. Por meio do pensar se pode auferir o valor das coisas e acontecimentos. O pensar, entretanto, também exige o concurso da formação para que o mesmo se constitua em algo genuinamente próprio e apropriado.

Apesar do exposto, não há garantias de que o pensar e o princípio da razoabilidade não possam ser distorcidos e canalizados para fins que não sejam o aperfeiçoamento e benefício do ser humano, da sociedade e do ecossistema. Não é novidade a compreensão de que o pensar também pode se ver aprisionado por princípios instrumentais completamente cegos quanto às repercussões humanas, sociais e naturais. Horkheimer e Adorno (1985), por exemplo, identificaram há muito a dimensão de dominação inscrita no âmago da razão, demonstrando cabalmente o quanto a mesma pode se tornar totalitária. Eis aqui, portanto, a necessidade de a própria reflexão também ser inspirada pelo princípio da igualdade 
derivado da compreensão da interconexão estabelecida entre os seres humanos e não-humanos. Seria uma grande discussão - fora do escopo deste artigo - definir se a admissão do princípio da igualdade é ou não derivado da razoabilidade. Quanto a isso, há muito tempo Kant (1781/1987) tomou a posição de que a razão seria impotente para sozinha provar a legitimidade de um princípio como esse; no entanto, tomando posição favorável à liberdade humana, Kant (1788/1986) reconhecera que apenas o sentido do dever prático que impulsiona à ação pode afirmar, ainda que não prove, a liberdade humana. Por isso mesmo, diante desse princípio, a razoabilidade consistiria na obediência à idéia de que o modo de agir legítimo é aquele cujo princípio pode ser aceito por todos. Só assim Kant pôde fazer integrar os princípios da igualdade e da razoabilidade.

Apesar de toda sofisticação do argumento kantiano, nada prova ser a razão a única fonte, ainda que indireta, da admissão da legitimidade da igualdade; Röhr (2000), por exemplo, considera que a admissão de princípios que dificilmente se podem legitimar apenas pela instância racional e o comprometimento pessoal com eles só podem ser acolhidos por meio da intuição, sendo esta que diretamente comunicaria a verdade daqueles, sem que se pudesse prová-los racionalmente. Entretanto, ainda que seja difícil identificar a origem do princípio da igualdade, nada impede reconhecer sua importância como elemento inspirador da reflexão, na medida em que a admissão da interconexão entre todos os seres, com o conseqüente reconhecimento da dignidade de cada um deles, termina por fomentar a reflexão no sentido de estabelecer para si parâmetros legítimos como aquele a que Kant acedeu ao enunciar o imperativo categórico. Observase, assim, uma circularidade e interconexão entre os princípios orientadores da igualdade, da verdade, da utilidade e da razoabilidade, assumidos como dimensões normativas da formação.

\section{Princípio da introspecção}

Além desses aspectos e princípios, outra dimensão normativa a ser ressaltada quanto à formação humana refere-se ao exercício da introspecção. Para alguns, essa capacidade ou habilidade seria simples decorrência do direcionamento da reflexão ao próprio interior. Embora não seja possível negar o fato de que o diálogo interior, de que fala Arendt (2000), se estabelece na introspecção como parte do esforço reflexivo que visa a alcançar uma significação plena para o sujeito, de outro lado, tal atividade interior também se expressa como um espaço da experiência e da contemplação. A despeito do fato de que experiência e contemplação não sejam atributos ou atividades restritas à ambiência interior, mas exercitemse também com relação à exterioridade, o aspecto aqui posto em relevo concebe a introspecção como aquela articulação entre reflexão, experiência e contemplação direcionada à interioridade e não ao espaço exterior. Desse modo, embora a natureza dessa tríade não seja originária e exclusiva do espaço interno, é necessário enfatizar que a competência no seu exercício em um desses âmbitos não é sinal de garantia de seu êxito no outro. Exemplificando, o cientista, filósofo, ou poeta que articulam suas experiências, reflexões e contemplação no que tange aos aspectos sociais, culturais, econômicos, políticos e interpessoais, não necessariamente se encontram familiarizados e estimulados a exercer a mesma maestria naquilo que concerne a seu interior. Assim, podem ser muito competentes, rigorosos e perspicazes quanto ao que ocorre no âmbito externo, mas incapazes, por exemplo, de compreender e lidar de forma satisfatória com a emergência de uma paixão ou de outro aspecto afetivo, isto porque sua atenção e perspicácia podem não estar desenvolvidas para auscultar com precisão os objetos internos. No entanto, sem o exercício e apropriação da reflexão, da experiência e contemplação, exercidas conjuntamente no que tange aos fenômenos do interior humano, não se pode desenvolver aquela finalidade a que o Relatório Jacques Delors se referiu como o "aprender a ser" (UNESCO, 1996/2003).

Quando a vida pessoal é vivida com sabedoria, a tendência é perceber que de fato não há separação entre introspecção e ação no mundo. Por meio da auto-reflexão, isto é, pelo exercício do diálogo interior, os hábitos mentais e comportamentais, os sentimentos e emoções podem se tornar progressivamente objeto da razoabilidade. Sem autocomiseração e inclemência, é possível que o indivíduo transforme seus limites, fraquezas, medos, potencialidades e virtudes em algo familiar, refletindo sobre eles e passando a chamar pelo devido nome cada uma de suas atitudes preponderantes, passando de fato a conhecê-las e a discernir-lhes o sentido, não apenas vivendo como seu refém. Por intermédio desse exame interno minucioso e freqüente, torna-se possível a pessoa contemplar com serenidade suas atitudes e hábitos mentais, se desembaraçando da padronização e repetição a que estava submetida por longo tempo. Por fim, por meio da experiência, tornar-se-á possível, gradualmente, agir de acordo com os princípios da própria auto-reflexão e contemplação; e, embora essa coerência não seja atingida imediatamente, surgirá gradualmente a percepção clara dos aspectos que resistem a se integrar e que pedem maior exame, reflexão ou aceitação, a fim de que a pessoa possa vir a aceitar-se como é e a assumir de fato a direção de si com plena lucidez, compreensão e coerência.

\section{Princípio da individuação}

Por outro lado, por intermédio da introspecção exercida pela auto-reflexão, contemplação e experiência, cada um poderá reconhecer seu constante inacabamento, tornando-se intimamente familiarizado com seus pensamentos, sentimentos e atitudes, a ponto de reconhecê-los com facilidade em si e nos outros, o que proporcionará o enriquecimento pessoal no sentido do desenvolvimento da compreensão, tolerância e paciência para com os demais. Assim, a autocompreensão tende a converter-se progressivamente em compreensão e 
aceitação da alteridade, o que implica, por sua vez, um comportamento mais sábio e familiarizado para com as diferenças já conhecidas e as que possam vir a surgir.

Com a progressiva, mas sempre inacabada realização nesse campo, o sujeito particular tenderá a sentir-se menos dividido; reconhecerá, a cada vez com maior clareza, que muitos dos obstáculos, ameaças e oposições, que antes costumava localizar na exterioridade, eram grandemente deformados por suas próprias projeções, hábitos mentais arraigados e pela falta de intimidade para consigo mesmo. Desse modo, muitas das obstinadas oposições "eu-mundo", "sujeito-objeto", passam a se fragilizar, permitindo ao sujeito particular experimentar um sentido paulatino de maior inteireza e integridade - surge, assim, a idéia de uma unificação progressiva consigo mesmo ou uma individuação, compreendida como o processo de superação contínua das diversas cisões interiores, o que permite que se dissipem muitas das oposições antes consideradas como conflito. Por outro lado, a realização progressiva da individuação também se articula com o fortalecimento do princípio da igualdade, na medida em que o indivíduo, pela sua própria trajetória, pode reconhecer no outro a mesma possibilidade de pacificação e unificação consigo mesmo.

\section{Princípio da liberdade}

Todos os princípios normativos até aqui analisados só se tornam, entretanto, educacionalmente pensáveis, realizáveis e só adquirem sua razão de ser quando assumidos sob o pressuposto da liberdade irredutível do ser humano. Desse modo, não há contradição alguma entre a assunção desse princípio e: (a) a admissão da igualdade entre as pessoas; (b) a aceitação do princípio axiológico da verdade como uma busca também definida pelas situações contextuais; (c) o reconhecimento de que a melhor forma de se empregar as possíveis habilidades pessoais é de um modo que simultaneamente promova a si mesmo e beneficie outras pessoas, com base no assentimento da própria interconexão da vida em geral. Para o reconhecimento de todos esses aspectos, no entanto, sempre será necessário o uso da razoabilidade e da introspecção, de forma que todos esses princípios se interrelacionem mutuamente.

Há, entretanto uma característica fundamental no princípio da liberdade que o diferencia de todos os demais e que se fundamenta necessariamente na singularidade do outro ser humano e em sua irredutível diferença. Esta é a razão pela qual a educação será sempre uma ciência e uma prática jamais completamente previsível. Isto também não significa que esta seja totalmente aleatória e sem nenhuma previsibilidade. Ninguém que conheça razoavelmente a psicologia do desenvolvimento humano nutrirá dúvida de que uma criança cujas experiências cruciais de socialização tenham sido marcadas pela rejeição terá grande probabilidade, salvo mudança radical de percurso, de desenvolver depressão ou padrões comportamentais agressivos, insegurança e dependência profundas. Isso atesta um certo grau de previsibilidade, porém sem jamais poder definir completamente o destino do ser humano. Esta também é a razão pela qual a educação jamais poderá fornecer uma garantia completa de seus resultados como sonham alguns burocratas, políticos, economistas e profissionais da própria educação. Aceitar isso é reconhecer a natureza abissal e livre do ser humano, sem negar, no entanto, várias componentes condicionantes, porém jamais totalizantes.

A liberdade humana, ao mesmo tempo em que é um dos aspectos mais aceitos pelo common sense, não deixa de ser também um grande mistério em sua profundidade. Somente por meio do recurso à liberdade, é possível, não explicar, mas tornar humanamente compreensíveis os atos que parecem transcender a própria humanidade como, por exemplo, $\mathrm{o}$ ato de renunciar à própria vida em favor de outrem ou a atitude de assumir completa e responsavelmente as totais consequências das próprias ações. Não é sem razão, portanto, que figuras como Sócrates, Jesus de Nazaré e algumas outras que se tornaram historicamente emblemáticas, tenham se convertido em apanágio humano ou em signo de adoração, como se, neste último caso, tivessem cruzado uma linha imaginária que os separaria do comum dos mortais. Atitudes assim, portanto, só podem ser, não explicadas, mas acolhidas quando se tem em mente a idéia da liberdade humana. Por outro lado, entretanto, também resulta quase sempre difícil explicar as razões que movem e moveram os grandes ditadores, déspotas e sanguinários do passado e do presente. Quando se recorda, por exemplo, que muitos representantes do alto escalão nazista, mas também dos assim intitulados "representantes do povo" no regime stalinista, ou nas diversas "ditaduras do proletariado" que existiram e ainda existem historicamente, eram amantes das artes ou de sofisticados debates intelectuais, chega-se à conclusão que o desenvolvimento intelectual, cognitivo e mesmo da sociabilidade não necessariamente garante um modo de viver autenticamente humano. A liberdade humana também surge aqui como um limite para a explicação do vir-a-ser de cada um e também da humanidade em geral.

Assim, sem descartar a idéia de uma determinada previsibilidade e, portanto, de uma determinada condição para preparar o caminho dos seres humanos de um modo digno e adequado à própria idéia regulativa do que a estes convém, essa tarefa terá sempre um grau de incerteza e inexatidão que não deriva de nenhuma falha intrínseca do educar, mas resulta da própria natureza do ser para o qual a educação se volta (Bollnow, 1959/1974).

A despeito da natureza ineliminável e imponderável da liberdade humana, a educação não pode se realizar como tal enquanto não a tiver como pressuposto e meta. Os princípios da igualdade, verdade, utilidade, razoabilidade, introspecção e individuação só podem valer como tais e se tornarem realmente efetivos na medida em que os mesmos passem a ser assumidos resoluta e livremente pelo ser humano. Isso significa que o caráter normativo da educação, tal como discutido, 
só se atualiza quando assumido livre e pessoalmente pelos sujeitos particulares, isto é, quando tudo o que é apropriado por estes passa a ter um significado e uma natureza própria em cada ser singular. Só quando essa realização interna é alcançada pode-se de fato reconhecer a realização da meta educacional. Ressalte-se sempre, entretanto, que tal realização será sempre dependente da contribuição, participação e volição do próprio ser humano em nome do qual toda a educação se estrutura.

Assim, para tornar mais claro o que aqui se afirma, a realização educacional de um ser particular irá proporcionar a aceitação própria, livre, sem coerção, do princípio da igualdade entre todos os seres humanos. Do mesmo modo, no exercício subjetivo de um juízo que não simplesmente designe o que uma coisa é, mas que se aprofunde igualmente na apreensão daquilo que deve ser - sem, no entanto, exercer violência sobre a natureza da coisa mesma que é objeto do pensamento, possibilitando ao mesmo tempo a adequação entre o pensador e o pensado -, o ser educado busca a verdade de um modo que, por sua própria natureza, só pode ser plenamente atualizada em um estado de liberdade do ser humano. Semelhantemente, o exercício de todas as habilidades e capacidades apropriadas e tornadas próprias de um modo que se expressem como realização pessoal e, ao mesmo tempo, como utilidade aos demais, é algo impossível de se descortinar em sua amplitude a não ser pelo exercício livre das capacidades de cada ser singular. Do mesmo modo, uma pessoa pode viver a vida praticamente inteira sem nunca levar a sério a introspecção. Nesse caso, possivelmente as realizações pessoais estarão quase sempre divorciadas umas das outras, ou sem que o indivíduo perceba ou construa internamente um sentido de articulação entre elas. Todavia, esse momento, ou melhor, essa atividade do espírito, por sua própria natureza, não pode existir se o sujeito livremente e por si mesmo não a empreender. Assim também ocorre com a individuação - sem o auto-exame e a auto-aceitação de si mesmo, o ser humano não progride na senda daquela unificação paulatina de suas divisões, a qual exige, como pressuposto básico, o livre reconhecimento de si e a supressão da violência para consigo mesmo, seja ela em que grau for.

Devido, portanto, à interpenetração da liberdade em todos os demais princípios mencionados, a educação jamais será aquela ciência exata ou completamente previsível com a qual tanto sonham vários planejadores e burocratas. Por outro lado, entretanto, uma vez admitido o valor axiológico de tais princípios, nenhuma realização social, política ou econômica que esteja orientada por ideais normativos humanos poderá prescindir da educação. E embora certamente esta última esteja longe de ser a condição e causa de todos os fenômenos sociais, políticos, culturais e econômicos, e nem de fato pretenda sê-lo, a mesma também não pode derivar sua natureza simplesmente das realizações ou da influência de um desses campos em particular ou da articulação deles entre si. Por essa razão é que, segundo tal compreensão, é completamente contraditório com a própria educação buscar determiná-la (o que não significa negar algumas influências e possíveis contribuições) com base exclusivamente em teorias que não a têm por objeto principal.

Eis, portanto, a importância de se compreender a educação com um sentido normativo de humanização que brota de sua própria constituição como campo de investigação e prática. Quando isso não ocorre, além de a educação se converter em apêndice de outras ciências ou de teorias elaboradas fora do âmbito educacional, as próprias repercussões práticas sobre o processo educativo tendem a se objetivar de um modo que contraria o seu próprio conceito. É por essa razão que surgiram no passado, permanecem de algum modo no presente e poderão ocorrer no futuro, dentro do próprio campo educacional ou fora dele, slogans que ganham força a cada investida da moda, mas que nem sempre surgem de questões eminentemente educacionais, tais como: "Educação para a revolução social"; "Educação para o desenvolvimento econômico"; "Educação para a cidadania"; "Educação para a competência", etc.

Assim, retomando o princípio da argumentação até aqui desenvolvida, a concepção da educação como teoria e prática formativas da humanidade do homem abrange não apenas uma descrição, mas igualmente uma dimensão normativa do ser humano. Tal normatividade, entretanto, não se dirige a conteúdos, mas a princípios, os quais também só encontram sua completa legitimidade no âmbito e processo da própria formação. Assim, os princípios da igualdade, da verdade, da utilidade, da razoabilidade, da introspecção, individuação e liberdade, não são passíveis de prova completa e exaustiva $a$ priori, mas dependem e exigem o concurso da experiência, processo único pelo qual o ser particular pode vir a se apropriar desses princípios, vivenciando-os, por conseqüência, de um modo autenticamente próprio.

\section{Considerações finais}

Os princípios normativos da educação ora apresentados - igualdade, verdade, utilidade, razoabilidade, introspecção, individuação e liberdade - não constituem uma lista exaustiva da idéia de formação humana. Certamente existem outras dimensões importantes a serem contempladas na formação, como, por exemplo, o princípio do belo. A perspectiva adotada aqui, no entanto, a despeito de sua incompletude, baseia-se na assunção de que sem esses princípios a educação também não se exerce segundo a idéia normativa que deve dirigi-la.

Desse modo, apresenta-se como fundamental ao âmbito educativo nutrir clareza sobre os princípios que configuram a natureza do educar. Sem uma clara compreensão da dimensão normativa da educação e de tais princípios, a própria idéia de possíveis contribuições de outros campos teóricos ou científicos pode mais obstar do que trazer benefícios à teoria e à prática da formação humana. Desse modo, a convicção intrínseca sobre aquilo em que consiste o pensar e o agir educativos, por parte dos educadores e do campo científico 
e teórico da educação, torna-se imprescindível para que o próprio diálogo com outras tradições, científicas ou não, possa ser empreendido. Só com base nisto as contribuições de outros campos e teorias podem ser de fato enriquecedoras ao núcleo da educação concebida como formação humana.

Finalmente, todos os princípios formativos aqui apresentados são relativos à apropriação pelo sujeito particular, não tendo sido mencionadas, senão indiretamente, as condições necessárias do ponto de vista objetivo (social, cultural, político, econômico) para que a educação se expresse amplamente como formação humana. Necessário se faz, por conseguinte, enfatizar que esses aspectos não são, de nenhuma forma, menos importantes do que os aqui analisados, mas, pelo contrário, é possível afirmar com segurança que uma sociedade, cultura, estrutura política ou econômica, atestam tanto mais seu grau de humanidade quanto expressam, estruturam e estimulam o desenvolvimento daqueles princípios formativos aqui analisados. De outra parte, este artigo não teve por objetivo analisar tais condições objetivas para que possa medrar de forma substantiva $o$ ato educativo. No entanto, como se pode depreender de tudo o que foi aqui analisado, sem o discernimento claro daqueles princípios fundamentais pode-se facilmente cair no extremo oposto das perspectivas teóricas que fazem residir os problemas e soluções educacionais apenas nas esferas social, econômica, política ou cultural, tendência essa que dá claros sinais de ser hegemônica no atual panorama educacional brasileiro, o que termina por transferir para as lógicas que operam nessas esferas a legitimidade de direcionar e estabelecer, de forma alienada e extrínseca, os princípios educacionais vigentes, reproduzindo, no campo educativo, as linhas de força que, do exterior, impingem àquele os aspectos negativos que os representantes daquelas esferas pretendem supostamente superar.

\section{Referências}

Arendt, H. (1999). Eichmann em Jerusalém: Um relato sobre a banalidade do mal (J. R. Siqueira, Trad.). São Paulo: Companhia das Letras. (Original publicado em 1963)

Arendt, H. (2000). A vida do espirito: O pensar, o querer, o julgar (A. Abranches, C. A. R. de Almeida, \& H. Martins, Trads.). Rio de Janeiro: Relume Dumará. (Original publicado em 1971)

Bollnow, F. (1974). Pedagogia e filosofia da existência: Um ensaio sobre formas instáveis de educação (H. Harada, Trad.). São Paulo: Vozes. (Original publicado em 1959)

Brandão, C. R. (1983). O que é educação. São Paulo: Brasiliense.

Castoriadis, C. (1992). As encruzilhadas do labirinto, III: O mundo fragmentado (R. M. Boaventura, Trad.). Rio de Janeiro: Paz e Terra. (Original publicado em 1990)

Horkheimer, M., \& Adorno, T. W. (1985). Dialética do esclarecimento: Fragmentos filosóficos (G. A. de Almeida, Trad.). Rio de Janeiro: Zahar. (Original publicado em 1944)
Jaeger, W. (2001). Paidéia: A formação do homem grego (A. M. Parreira, Trad.). São Paulo: Martins Fontes. (Original publicado em 1936)

Kant, I. (1986). Crítica da razão prática (A. Morão, Trad.). Lisboa: Edições 70. (Original publicado em 1788)

Kant, I. (1987). Crítica da razão pura (V. Rohden \& U. B. Moosburger, Trads., Coleção Os Pensadores). São Paulo: Nova Cultural. (Original publicado em 1781)

Marcuse, H. (1978). Razão e revolução: Hegel e o advento da teoria social (M. Barroso, Trad.). Rio de Janeiro: Paz e Terra. (Original publicado em 1941)

Marcuse, H. (1979). A ideologia da sociedade industrial: $O$ homem unidimensional (G. Rebuá, Trad.). Rio de Janeiro: Zahar. (Original publicado em 1966)

Organização das Nações Unidas para a Educação, a Ciência e a Cultura. (2003). Educação: Um tesouro a descobrir: Relatório para a UNESCO da Comissão Internacional sobre Educação para o século XXI (J. C. Eufrázio, Trad.). São Paulo: Cortez. (Original publicado em 1996)

Röhr, F. (1999) A multidimensionalidade na formação do educador. Revista de Educação AEC, 28, 100-108.

Röhr, F. (2000). Intuição e formação do educador. Revista de Educação - AEC, 29, 123-140.

José Policarpo Junior é Professor Adjunto do Centro de Educação da Universidade Federal de Pernambuco e pesquisador do Instituto de Pesquisas para a Promoção da Formação Humana (Recife, PE).

Maria Lucicleide Falcão de Melo Rodrigues é Professora Assistente do Centro de Filosofia e Ciências Humanas da Universidade Federal de Pernambuco e professora do Instituto de Pesquisas para a Promoção da Formação Humana (Recife, PE).

Recebido: 23/07/2008

$1^{a}$ revisão: 30/06/2009

$2^{a}$ revisão: 04/05/2009

Aceite final: 28/06/2009 